\title{
Optimalisasi Model Asuhan Keperawatan Profesional Tim Di Ruang S RS X Bogor
}

\author{
Sancka Stella Ganiasda Sihura ${ }^{1}$, Agus Purnama ${ }^{2}$, Eka Rokhmiati ${ }^{3}$ \\ Departement : Jl.Harapan $50 \mathrm{Gd}$.HZ Lenteng Agung \\ (STIKes Indonesia Maju, Departemen Keperawatan, Indonesia) \\ Email : stellasancka@gmail.com
}

\section{Artikel Info \\ Ciptaan disebarluaskan di bawah Lisensi Creative \\ Commons Atribusi- \\ BerbagiSerupa 4.0 \\ Internasional.}

Kata Kunci : metode tim, ronde keperawatan, hand over, conference

\begin{abstract}
Abstrak
Latar Belakang: Hasil pengkajian mengidentifikasi adanya kendala dalam pelaksanaan metode asuhan keperawatan professional tim yang berdampak pada penurunan kepuasan pasien terhadap asuhan keperawatan saat masa hospitalisasi. Tujuan: penelitian ini bertujuan untuk mengidentifikasi akar penyebab masalah yang ditemukan dan menemukan inovasi sebagai landasan perubahan dalam area rumah sakit. Metode: Penulis menggunakan metode studi kasus. Hasil: Faktor pre dan post conference yang belum optimal, ketidaktepatan waktu pelaksanaan handover, dan belum dilaksanakannya sosialisasi ronde keperawatan mempengaruhi ketidakoptimalan implementasi metode asuhan keperawatan professional tim. Kesimpulan: sosialisasi ronde manajemen keperawatan efektif dalam meningkatkan pengetahuan dan pengalaman perawat untuk meningkatkan optimalisasi pelaksanaan meode asuhan keperawatan tim. Ronde keperawatan dapat membantu perawat dalam menemukan solusi pemecahan masalah yang kompleks terkait asuhan keperawatan. Manajer perlu melaksanakan peran dan fungsi manajerial secara tepat agar proses implementasi asuhan keperawatan tim bisa dilaksanakan secara optimal
\end{abstract}

\section{Pendahuluan}

Rumah Sakit merupakan unit pelayanan kesehatan dari sistem pelayanan kesehatan dan merupakan unsur strategis, dimana sebagian besar dana kesehatan terserap dalam sektor pengelolaan rumah sakit baik di negara maju maupun di negara berkembang. Pelayanan medik dan keperawatan merupakan sub sistem dari sistem pelayanan yang ada di rumah sakit. Bentuk pelayanan yang diberikan berpusat pada keadaan pasien, sehingga lebih bersifat individual yang disebut patient centered care. ${ }^{1}$ Tuntutan masyarakat terhadap kualitas pelayanan keperawatan di rumah sakit dirasakan sebagai suatu fenomena yang harus dijadikan perhatian. Oleh karena itu pelayanan keperawatan ini perlu mendapat prioritas utama dalam pengembangan ke masa depan. Perawat mengembangkan ilmu pengetahuannya dan berubah sesuai tuntutan masyarakat, dan menjadi tenaga perawat yang professional. Pengembangan dalam berbagai aspek keperawatan bersifat saling berhubungan, saling bergantung, saling mempengaruhi dan saling berkepentingan oleh karena itu inovasi dalam pendidikan keperawatan, praktek keperawatan, ilmu keperawatan dan kehidupan keprofesian merupakan fokus utama keperawatan Indonesia dalam proses profesionalitas, sehingga perlu adanya manajemen keperawatan. $^{2}$ 
Manjemen merupakan suatu pendekatan yang dinamis dan proaktif dalam menjalankan suatu kegiatan organisasi. Sedangkan manajemen keperawatan adalah proses bekerja melalui anggota staff keperawatan untuk memberikan asuhan keperawatan secara professional. Proses manajemen keperawatan sejalan dengan proses keperawatan sebagai suatu metode pelaksanaan asuhan keperawatan secara professional, sehingga diharapkan keduanya saling menopang. Sebagaimana yang terjadi di dalam proses keperawatan, di dalam manajemen keperawaatan pun terdiri dari pengumpulan data, identifikasi masalah, perencanaan, pelaksanaan dan evaluasi hasil. Manajemen keperawatan harus dapat diaplikasikan dalam tatanan pelayanan nyata di Rumah Sakit, sehingga perawat perlu memahami bagaimana konsep dan aplikasinya di dalam organisasi keperawatan itu sendiri. ${ }^{3}$ Dari hasil observasi dan wawancara yang dilakukan oleh Mahasiswa Profesi Ners Sekolah Tinggi IImu Kesehatan Indonesia Maju (STIKIM) yang berpraktek manajemen keperawatan di Ruang S RS X Bogor, ditemukan data bahwa pengelolaan manajemen pelayanan dan manajemen asuhan keperawatan masih ada yang tidak sesuai dengan proses penerapan manajemen, terutama terkait pelaksanaan pre-post confrence, hand over dan ronde keperawatan. Kurang on time nya jadwal timbang terima sehingga pelaksanaan tidak optimal, dan sosialiasi ronde keperawatan yang hanya disampaikan kepada ketua tim. Oleh karena itu, penulis tertarik untuk menganalisis implementasi ronde keperawatan dan intervensi yang tepat untuk meningkatkan kualitas hand over dan ronde keperawatan, penelitian ini bertujuan untuk mengidentifikasi akar penyebab masalah yang ditemukan dan menemukan inovasi sebagai landasan perubahan dalam area rumah sakit.

\section{Metode}

Studi kasus dilakukan untuk menganalisis pelaksanaan ronde keperawatan di RS X. Pengumpulan data dilakukan dengan menelaah dokumen, wawancara, dan kuesioner yang disebarkan kepada tenaga keperawatan yang telah bekerja lebih dari tiga tahun di ruangan S RS $X$ Bogor, dan kepada kepala ruangan juga ketua tim yang bekerja di ruangan tersebut. Analisis situasi dilakukan dengan analisis tulang ikan/fish bone dengan tujuan mengidentifikasi factorfaktor penyebab ketidakoptimalan pelaksanaan hand over dan ronde keperawatan, kemudian dibuat rencana tindakan bersama dengan kepala ruangan, ketua tim dan perawat pelaksana berdasarkan permasalahan yang ada. Analisis didasarkan pada peran dan fungsi manajemen keperawatan

\section{Hasil}

Berdasarkan hasil intrumen observasi berdasar pedoman pre dan post conference, ketua tim tidak membagi alokasi waktu secara jelas, sehingga pelaksaan tidak optimal. Selain itu, ketua tim belum memberikan tindak lanjut terkait asuhan keperawatan yang diberikan. Tindak lanjut disampaikan kepada perawat pelaksana dalam rangka memberikan pengarahan terkait intervensi asuhan yang akan dilakukan kepada pasien kelolaan di hari itu. Ketua tim tidak memberikan reinforcement positif kepada anggota tim, dan juga pre conference yang tidak dilaksanakan tepat waktu, sehingga resiko terjadi kekurangan waktu dalam penyampaian data kondisi pasien, dan meningkatkan resiko missed communication. Berdasarkan hasil instrumen observasi pedoman pre dan post conference, ditemukan sebanyak $67 \%$ pre dan post confrence tidak dilakukan dan $33 \%$ dilakukan. Berdasarkan hasil wawancara tanggal 23 Juni 2021 pada kepala ruangan, didapatkan bahwa ruang $S$ telah menerapkan metode asuhan keperawatan tim, sehingga sudah pernah dilakukan pengenalan terkait dengan ronde keperawatan yang menunjang terlaksananya kesinambungan perawatan. 
Tabel 1. Kualifikasi Tenaga Keperawatan di Ruang S RS X Bogor

\begin{tabular}{|c|c|c|c|}
\hline No & Pendidikan & $\Sigma$ & $\%$ \\
\hline 1 & S1 Ners & 3 & 20 \\
\hline 2 & D3 Keperawatan & 12 & 80 \\
\hline & Jumlah & 15 & 100 \\
\hline
\end{tabular}

Tabel di atas menunjukan data tenaga keperawatan di Ruang Saraswati dengan jumlah total 15 orang, dengan kategori perawat yang pendidikannya S1 Ners berjumlah 3 (20\%), dan D3 Keperawatan berjumlah $12(80 \%)$. Ketua tim mengatakan keseluruhan dari perawat belum mendapatkan sosialisasi terkait ronde keperawatan. Identifikasi masalah diilustrasikan dalam analisis fish bone di bawah ini:

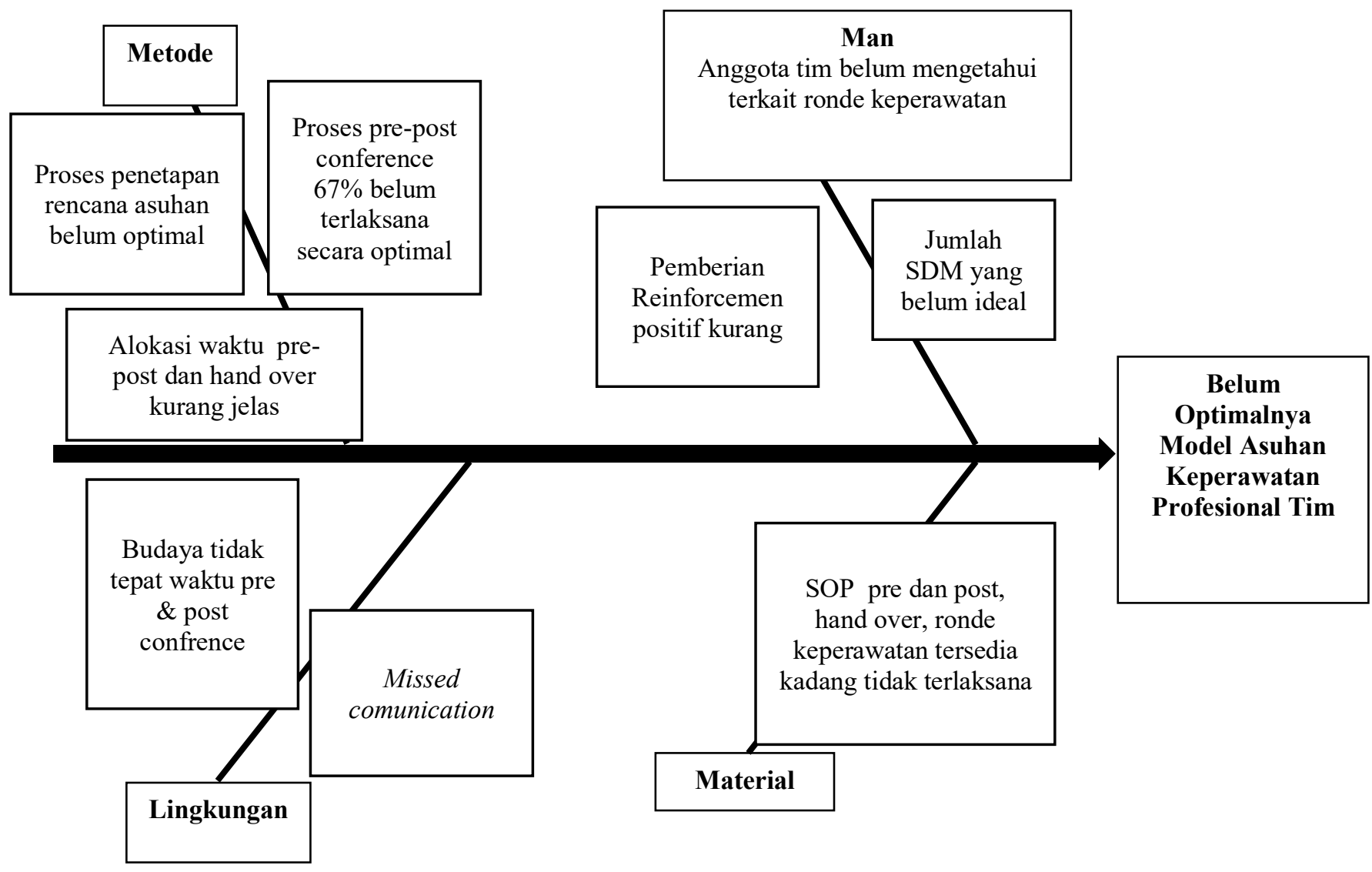

Gambar 1. Fish Bone Ruang S RS X Bogor

Permasalahan yang berhasil diidentifikasi, dipertimbangkan berdasarkan waktu, keterbatasan sumber daya, dan kewenangan atau kemampuan mengatasi masalah yang ada, sehing a masalah yang akan diatasi adalah maslaah yang termasuk prioritas utama. Hasil identifikasi data di ruangan ditemukan beberapa masalah yang timbul, sehingga penulis membuat table prioritas masalah untuk menentukan masalah yang terlebih dahulu harus diselesaikan. Proses melakukan prioritas masalah dilakukan dengan mempehatikan aspek kecenderungan besar dan seringnya masalah tersebut, besarnya kerugian yang ditimbulkan dari masalah, bisa dipecahkan, melibatkan pertimbangan dan perhatian perawat, dan ketersediaan sumber daya. 
Masalah yang ditemukan tidak hanya terkait belum optimalnya model asuhan keperawatan profesioanl tim, tetapi masalah ini menjadi maslaah yang palong prioritas setelah dihitung menggunakan table prioritas masalah.

Tabel 2. Prioritas Masalah

\begin{tabular}{clcccccc}
\hline NO & \multicolumn{1}{c}{ Masalah } & Mg & Sv & Mn & Ne & Af & SKOR \\
\hline $\mathbf{1}$ & $\begin{array}{l}\text { Kekurangan SDM di } \\
\text { Ruang saraswati }\end{array}$ & $\mathbf{5}$ & $\mathbf{5}$ & $\mathbf{5}$ & $\mathbf{5}$ & $\mathbf{3}$ & $\mathbf{1 8 7 5}$ \\
\hline $\mathbf{2}$ & $\begin{array}{l}\text { Pemeliharaan gedung } \\
\text { pengecatan dinding } \\
\text { terkelupas Ruang Ka Ru } \\
\text { belum terpisah } \\
\text { Media tanaman }\end{array}$ & $\mathbf{3}$ & $\mathbf{3}$ & $\mathbf{3}$ & $\mathbf{3}$ & $\mathbf{4}$ & $\mathbf{3 2 4}$ \\
\hline $\mathbf{3}$ & $\begin{array}{l}\text { Belum Optimalnya } \\
\text { Model Asuhan } \\
\text { Keperawatan } \\
\text { Profesional Tim }\end{array}$ & $\mathbf{5}$ & $\mathbf{5}$ & $\mathbf{5}$ & $\mathbf{4}$ & $\mathbf{5}$ & $\mathbf{2 5 0 0}$ \\
\hline
\end{tabular}

Tabel 3. Seleksi Alternatif Penyelesaian Masalah

\begin{tabular}{|c|c|c|c|c|c|c|}
\hline No & Kegiatan & $\mathrm{Ca}$ & $\mathbf{A b}$ & Rc & Ld & Skor \\
\hline 1 & $\begin{array}{l}\text { Melakukan role play pre dan post conference } \\
\text { untuk meningkatkan pengetahuan perawat } \\
\text { pelaksana }\end{array}$ & 3 & 5 & 4 & 4 & 240 \\
\hline 2. & $\begin{array}{l}\text { Membuat banner terkait waktu pelaksanaan } \\
\text { hand over dan pelaksanaan hand over secara } \\
\text { SBAR }\end{array}$ & 3 & 3 & 5 & 3 & 135 \\
\hline 3. & $\begin{array}{l}\text { Melakukan resosialisasi terkait standar } \\
\text { operasional prosedur ronde keperawatan di } \\
\text { ruangan }\end{array}$ & 4 & 4 & 5 & 5 & 400 \\
\hline
\end{tabular}

Hasil perhitungan table seleksi alternatif masalah yang menjadi prioritas adalah pelaksanaan Melakukan resosialisasi terkait standar operasional prosedur ronde keperawatan di ruangan.

\section{Pembahasan}

Hasil pengkajian menyatakan bahwa pengelolaan manajemen pelayanan dan manajemen asuhan keperawatan masih ada yang tidak sesuai dengan proses penerapan manajemen yang benar. Hal ini dapat dilihat dari kurang optimalnya pelaksanaan metode asuhan keperawatan profesional tim. Dari data yang didapatkan tampak handover tidak dilakukan secara optimal, pre-dan post conference yang belum dilakukan $100 \%$, dan ketidaktepatan waktu saat memulai timbang terima. Selain itu, belum menyeluruhnya pengetahuan terkait dengan ronde keperawatan pada seluruh perawat pelaksana. Ketidaktepatan timbang terima sebelum memulai implementasi asuhan keperawatan akan perpengaruh terhadap terganggunya asuhan keperawatan yang diberikan. ${ }^{4}$ menemukan bahwa serah terima/handover yang buruk dapat menyebabkan keterlambatan pelayanan, ketidak tepatan waktu yang berdampak pada efisiensi dan efektivitas serta tingkat kepuasan pasien yang akan menurun terhadap penyedia layanan kesehatan, termasuk perawat. Manajemen mendefinisikan manajemen keperawatan sebagai proses pelaksanaan pelayanan keperawatan melalui upaya staff keperawatan untuk memberikan Asuhan 
Keperawatan, pengobatan dan rasa aman kepada pasien, keluarga, kelompok dan masyarakat (Gillies, 2002). Manajemen keperawatan mempunyai lingkup manajemen operasional yang merencanakan, mengatur, dan menggerakkan para karyawannya untuk memberikan pelayanan keperawatan yang sebaikbaiknya kepada pasien melalui manajemen Asuhan Keperawatan. Agar dapat memberikan pelayanan keperawatan dengan sebaik-baiknya, maka diperlukan suatu Standard Asuhan Keperawatan (SAK) yang akan digunakan sebagai target maupun alat kontrol pelayanan tersebut. ${ }^{4}$

Pada fungsi manajemen keperawatan terdapat beberapa elemen utama yaitu Planning (perencanaan), Organizing (pengorganisasian), Staffing (kepegawaian), Directing (pengarahan), Controlling (pengendalian/evaluasi). Fungsi planning (perencanaan) adalah fungsi terpenting dalam manajemen, oleh karena fungsi ini akan menentukan fungsi-fungsi manajemen lainnya. Fungsi perencanaan merupakan landasan dasar dari fungsi manajemen secara keseluruhan. Tanpa ada fungsi perencanaan tidak mungkin fungsi manajemen lainnya akan dapat dilaksanakan dengan baik. ${ }^{5}$ Perencanaan akan memberikan pola pandang secara menyeluruh terhadap semua pekerjaan yang akan dijalankan, siapa yang akan melakukan, dan kapan akan dilakukan. Perencanaan merupakan tuntutan terhadap proses pencapaian tujuan secara efektif dan efesien. Swanburg (2000) mengatakan bahwa planning adalah memutuskan seberapa luas akan dilakukan, bagaimana melakukan dan siapa yang melakukannya. ${ }^{6}$ Dibidang kesehatan perencanaan dapat didefenisikan sebagai proses untuk menumbuhkan, merumuskan masalah-masalah kesehatan di masyarakat, menentukan kebutuhan dan sumber daya yang tersedia, menetapkan tujuan program yang paling pokok, dan menyusun langkahlangkah untuk mencapai tujuan yang telah ditetapkan tersebut. Pengorganisasian adalah suatu langkah untuk menetapkan, menggolongkan dan mengatur berbagai macam kegiatan, penetapan tugas-tugas dan wewenang seseorang, pendelegasian wewenang dalam rangka mencapai tujuan. Fungsi pengorganisasian merupakan alat untuk memadukan semua kegiatan yang beraspek personil, finansial, material dan tata cara dalam rangka mencapai tujuan yang telah ditetapkan. ${ }^{7}$ Staffing merupakan metodologi pengaturan staff, proses yang teratur, sistematis berdasarkan rasional yang diterapkan untuk menentukan jumlah personil suatu organisasi yang dibutuhkan dalam situasi tertentu. ${ }^{8}$

Proses pengaturan staff bersifat kompleks. Komponen pengaturan staff adalah sistem kontrol termasuk studi pengaturan staff, penguasaan rencana pengaturan staff, rencana penjadwalan, dan Sistem Informasi Manajemen Keperawatan (SIMK). ${ }^{9}$ SIMK meliputi lima elemen yaitu kualitas perawatan pasien, karakteristik dan kebutuhan perawatan pasien, perkiraan suplai tenaga perawat yang diperlukan, logistik dari pola program pengaturan staf dan kontrolnya, evaluasi kualitas perawatan yang diberikan. ${ }^{10}$ Dasar perencanaan untuk pengaturan staff pada suatu unit keperawatan mencakup personil keperawatan yang bermutu harus tersedia dalam jumlah yang mencukupi dan adekuat, memberikan pelayanan pada semua pasien selama 24 jam sehari, 7 hari dalam seminggu, 52 minggu dalam setahun. Setiap rencana pengaturan staff harus disesuaikan dengan kebutuhan rumah sakit dan tidak dapat hanya dicapai dengan rasio atau rumusan tenaga/pasien yang sederhana. Jumlah dan jenis staff keperawatan yang diperlukan dipengaruhi oleh derajat dimana departemen lain memberikan pelayanan pendukung, juga dipengaruhi oleh jumlah dan komposisi staff medis dan pelayanan medis yang diberikan. Kebutuhan khusus individu, dokter, waktu dan lamanya ronde, jumlah test, obat-obatan dan pengobatan, jumlah dan jenis pembedahan akan mempengaruhi kualitas dan kuantitas personel perawat yang diperlukan dan mempengaruhi penempatan mereka. ${ }^{11}$

Pengaturan staff kemudian juga dipengaruhi oleh organisasi divisi keperawatan. Rencana harus ditinjau ulang dan diperbaharui untuk mengatur departemen beroperasi secara efisien dan ekonomis dengan pernyataan misi, filosofi dan objektif tertulis, struktur organisasi, fungsi dan tanggung jawab, kebijakan dan prosedur tertulis, pengembangan program staff efektif, dan evaluasi periodik terencana. Pengarahan adalah hubungan antara aspek-aspek individual yang ditimbulkan oleh adanya pengaturan terhadap bawahan-bawahan untuk dapat dipahami dan pembagian pekerjaan yang efektif untuk tujuan perusahaan yang nyata. Kepemimpinan merupakan faktor penting dalam keberhasilan manajemen. ${ }^{12}$, kepemimpinan adalah suatu proses yang mempengaruhi aktivitas kelompok terorganisasi dalam upaya menyusun dan mencapai tujuan. Gardner dalam Swanburg (2000), menyatakan bahwa kepemimpinan sebagai suatu proses persuasi dan memberi contoh sehingga individu (pimpinan kelompok) membujuk kelompoknya untuk mengambil tindakan yang sesuai dengan usulan pimpinan atau usulan bersama.

\section{Kesimpulan}

Studi kasus ini menyimpulkan bahwa sosialisasi ronde manajemen keperawatan efektif dalam meningkatkan pengetahuan dan pengalaman perawat untuk meningkatkan optimalisasi pelaksanaan 
meode asuhan keperawatan tim. Ronde keperawatan dapat membantu perawat dalam menemukan solusi pemecahan masalah yang kompleks terkait asuhan keperawatan. Manajer perlu melaksanakan peran dan fungsi manajerial secara tepat agar proses implementasi asuhan keperawatan tim bisa dilaksanakan secara optimal.

\section{Deklarasi Konflik Kepentingan}

menyatakan bahwa penelitian ini independen dari konflik kepentingan individu dan organisasi.

\section{Ucapan Terimakasih}

Terimakasih kepada tim manajemen dan RS yang telah membantu proses penelitian ini

\section{Referensi}

1. Riskiyah, Riskiyah, Tita Hariyanti, and Siti Juhariah. "Pengalaman Pasien Rawat Inap terhadap Penerapan Patient Centered Care di RS UMM." Jurnal Kedokteran Brawijaya 29.4 (2017): 358363.

2. Hidayah, Nur. "Manajemen model asuhan keperawatan profesional (MAKP) tim dalam peningkatan kepuasan pasien di rumah sakit." Jurnal kesehatan 7.2 (2014): 114-141.

3. Gillies, Ann. Nursing Management: A System Approach. W.B. Saunders Company : U.K; 2000.

4. Nogo, Antonia. "Kinerja Perawat dalam Penerapan Standar Asuhan Keperawatan di Rumah Sakit Umum Daerah Naibonat Kabupaten Kupang." Jurnal Penelitian 18.1 (2014).

5. Rahardjo, Sutio, Sri Wayanti Wayanti, and Novita Eka Kusuma Wardani. "Pengaruh Fungsi Manajemen Pelaksana Kegiatan SDITK terhadap Cakupan SDITK Balita \& Anak Prasekolah." Pamator Journal 12.1 (2019): 5-11.

6. Julianto, Mito, and R. S. U. P. Soelarto. "Peran dan Fungsi Manajemen Keperawatan dalam Manajemen Konflik." Jurnal Rumah Sakit Fatmawati (2016).

7. Nazlen, Cut Bunga Maharani. "Administrasi Pendidi Dan Tenaga Kependidikan 1." (2020).

8. Wulandari, Dyah Fitri, and Hanny Handiyani. "Pengembangan Dokumentasi Keperawatan Berbasis Elektronik Di RS X Kota Depok Dengan Menggunakan Teori Perubahan Lewins." (JKG) Jurnal Keperawatan Global 4.1 (2019): 55-64.

9. Wulandari, Cicilia Ika, and Andi A. Wildani. "Realisasi Rencana Strategis Kepala Bidang Keperawatan dalam Menerapkan Sistem Informasi Manajemen Keperawatan." Journal of Holistic Nursing Science 6.2 (2019): 58-63.

10. Ramadina, Syahrina, and Samsul Hadi. "Pengembangan sistem informasi manajemen bengkel kerja sekolah menengah kejuruan." Jurnal Pendidikan Vokasi 5.1 (2015): 103-116.

11. Hidayah, Nur. "Manajemen model asuhan keperawatan profesional (MAKP) tim dalam peningkatan kepuasan pasien di rumah sakit." Jurnal kesehatan 7.2 (2014): 114-141.

12. Julianto, Mito, and R. S. U. P. Soelarto. "Peran dan Fungsi Manajemen Keperawatan dalam Manajemen Konflik." Jurnal Rumah Sakit Fatmawati (2016). 